\title{
Infiltrating giant cell tumor in a case of Paget's disease of bone
}

\author{
Vincenzo Nuzzo • T. Ferrara • Alfonso Zuccoli • \\ Raffaella Brunetti-Pierri • Roberto De Rosa • \\ Alberto Falchetti • R. Franco • Nicola Brunetti-Pierri
}

Received: 24 March 2009 / Accepted: 2 June 2009 / Published online: 6 August 2009

(C) The Author(s) 2009. This article is published with open access at Springerlink.com

\begin{abstract}
Giant cell tumor (GCT) of the bone, also called osteoclastoma, is a rare complication of Paget's bone disease. We report a patient from Southern Italy who developed a GCT infiltrating the neighboring tissues. The natural history and the therapeutic outcomes of this unique complication of Paget's bone disease are presented.
\end{abstract}

Keywords Paget's bone disease · Giant cell tumors . Osteoclastoma

\section{Introduction}

Paget's disease of bone (PDB) is a common slowly progressive disorder due to abnormal ostoclastic-osteoblastic

V. Nuzzo $(\bowtie) \cdot$ T. Ferrara • A. Zuccoli • R. Brunetti-Pierri Internal Medicine Unit, "S. Gennaro" Hospital,

Via San Gennaro dei Poveri, 25,

Naples, Italy

e-mail: vincenzo.nuzzo@libero.it

R. De Rosa

Radiology Unit, "S. Gennaro" Hospital,

Naples, Italy

A. Falchetti

Department of Internal Medicine,

University of Florence- “Centro di Riferimento Regionale

Tumori Endocrini Ereditari” AOUC,

Florence, Italy

R. Franco

National Cancer Institute G. Pascale, Section of Pathology,

Naples, Italy

N. Brunetti-Pierri

Department of Pediatrics, Federico II University of Naples, Naples, Italy remodeling resulting in deformity and enlargement of single or multiple bones. The cause of PDB is incompletely understood, but genetic factors have clearly an important role as roughly, $15 \%$ of patients have a positive family history. Moreover, mutations causing this disease or related syndromes have been identified in four genes [1]. The most important gene for PDB is Sequestosome 1 (SQSTM1/p62) encoding a protein implicated in pre-osteoclast recruitment and maturation and a molecular partner of the NFkBsignaling pathway [2]. Several other loci have been identified by genome-wide linkage association studies [3].

Major complications of PDB include bone deformities and fractures, osteoarthritis, and more rarely, high-output cardiac failure. The development of malignancy, usually osteosarcomas, is reported to occur in $<1 \%$ of cases [4-6]. The majority of these tumors are classified as osteogenic osteosarcomas [7], but benign giant cell tumors (GCTs), otherwise known as osteoclastomas, may also occur [8]. GCTs occur more frequently in patients with the polyostotic form of PDB and usually involve the skull and facial bones and, less frequently, the pelvis and the spine. These tumors are histological and clinically benign and they usually remain confined to the affected bone.

\section{Case report}

We report the case of a male patient from the region of Campania, a region of Southern Italy including the town of Avellino, who was first diagnosed with a polyostotic PDB at the age of 35 years. His medical history was significant for obesity, diverticulosis, benign prostatic hypertrophy, and mild hearing loss. The PDB was under control without any medical treatment until the age of 68 years when the patient developed back pain which was initially mild and localized, 
but it progressively worsened and extended to the lumbar and left iliac region. The pain was more severe with physical activity and was only partially relieved by NSAIDs. A slow-growing palpable mass in the left anterior abdominal region and a single episode of hematuria were also reported. He had no history of fracture. His family history was significant for his daughter who was also affected by PDB diagnosed when she was 20 years old and treated with biphosphonate. The physical examination confirmed the presence of a firm mass extending from the left iliac bone to the anterior abdominal region. The ultrasound and the abdominal-pelvic CT scan both indicated the presence of a lesion with irregular margins, with a diameter of approximately $8 \mathrm{~cm}$ and tightly adherent to the ileum and left ischio-pubic bones (Fig. 1). The lesion was found to infiltrate the rectum, the distal portion of the left ureter and the bladder. The X-rays of the pelvis (Fig. 2) and lower limbs showed cortical thickening and sclerosis of the multiloculated lytic lesions of the iliac bones. The cortex of the long bones of both upper and lower extremities was coarse and thickened. The bone scintigraphy showed increased uptake in multiple sites including the skull, vertebral bodies, proximal regions of the humeri, pelvic bones, and proximal femurs bilaterally (Fig. 3). His total serum alkaline phosphatase activity $(1,346 \mathrm{IU} / \mathrm{L}$; normal range, $8-300 \mathrm{IU} / \mathrm{L})$ and bone-specific fraction $(230.3 \mathrm{IU} / \mathrm{L}$; normal range: 6-16 IU/L) were both significantly elevated. PTH (18.3 pg/ml; normal range $10-65 \mathrm{pg} / \mathrm{ml})$, urinary deoxypyridoline (3.8 UI; normal range, 2.5-5.5 UI), osteocalcin $(13.4 \mathrm{ng} / \mathrm{ml}$; normal range, $5-18 \mathrm{ng} / \mathrm{ml}), 25-0 \mathrm{HD}$ (22.6 ng/ml; normal range, 9.2-45.2 $\mathrm{ng} / \mathrm{ml})$, ESR, and Creactive protein were all within the normal ranges.

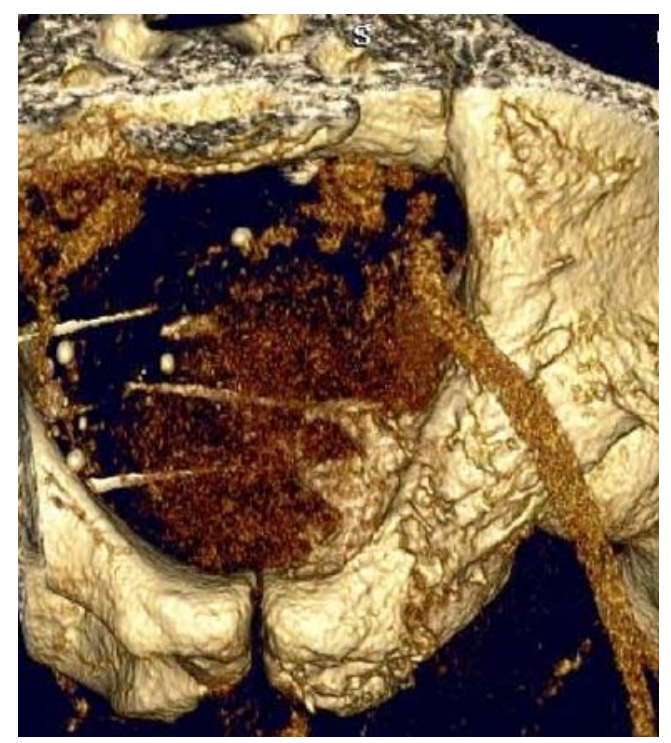

Fig. 1 3D-CT scan of the tumor lesion showing irregular margins, with a diameter of approximately $8 \mathrm{~cm}$ and tightly adherent to the ileum and left ischio-pubic bones

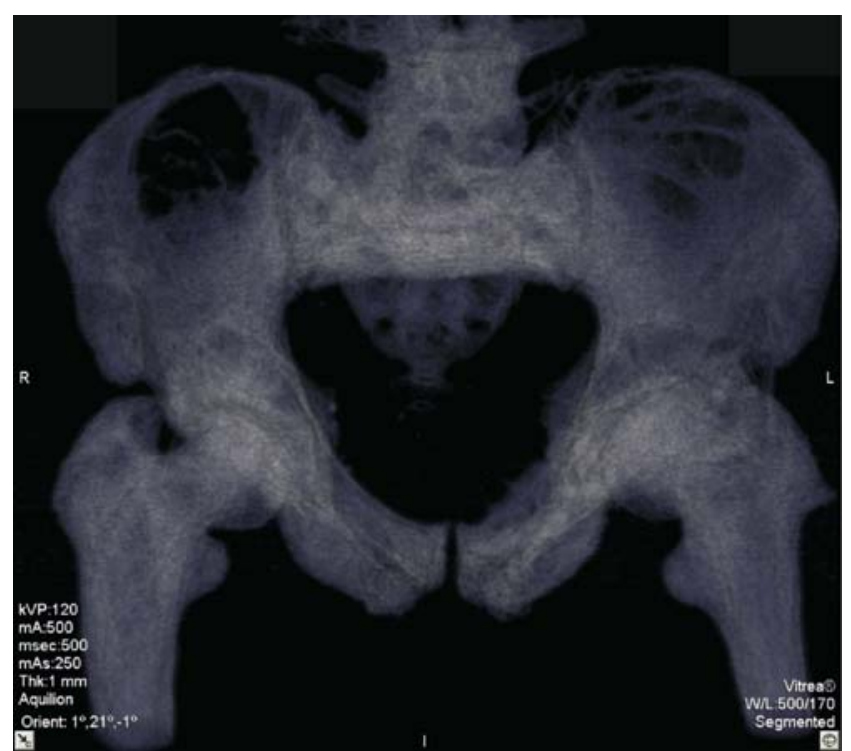

Fig. 2 Pelvis X-ray showing the typical mixed appearance of areas of osteolysis and sclerosis

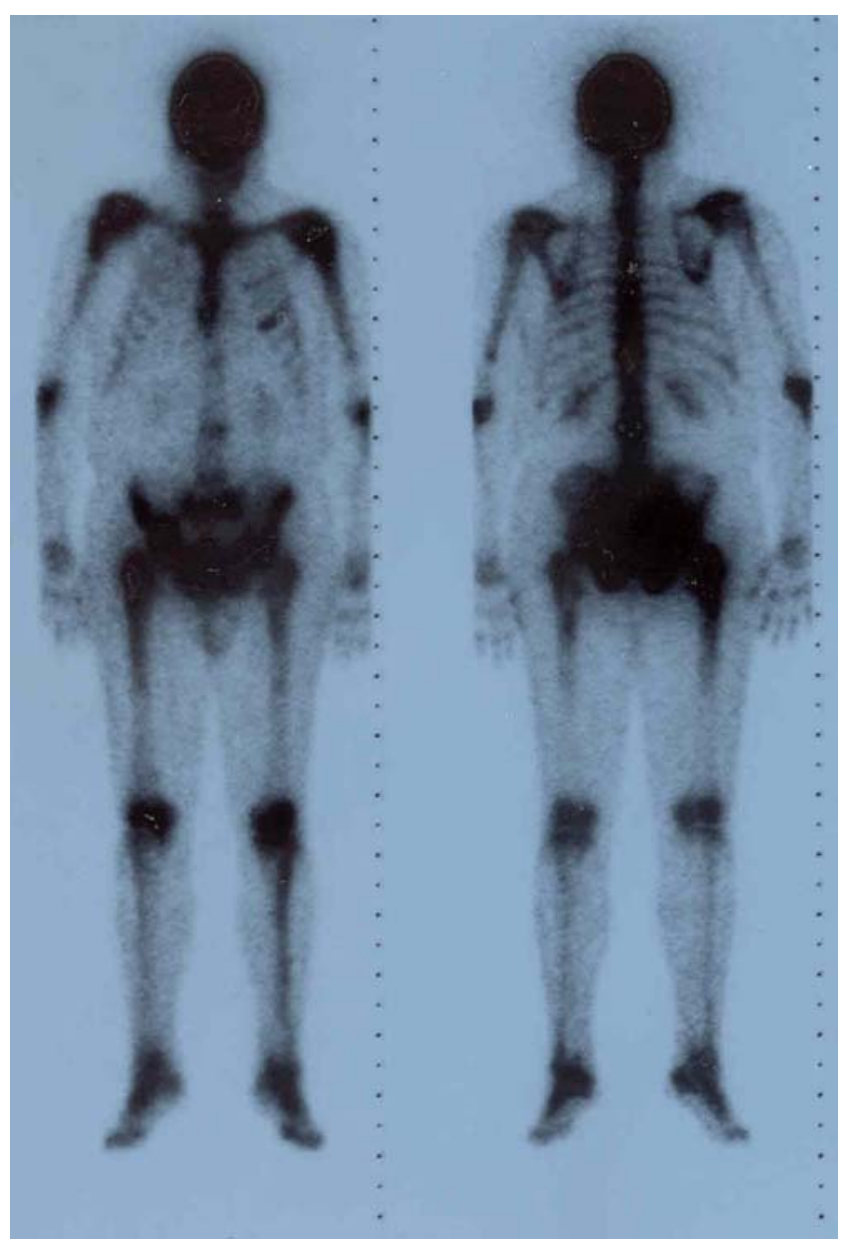

Fig. 3 Anterior (left) and posterior (right) technetium-99m-labeled diphosphonate bone scintigraphy showing multiple sites of increased uptake 

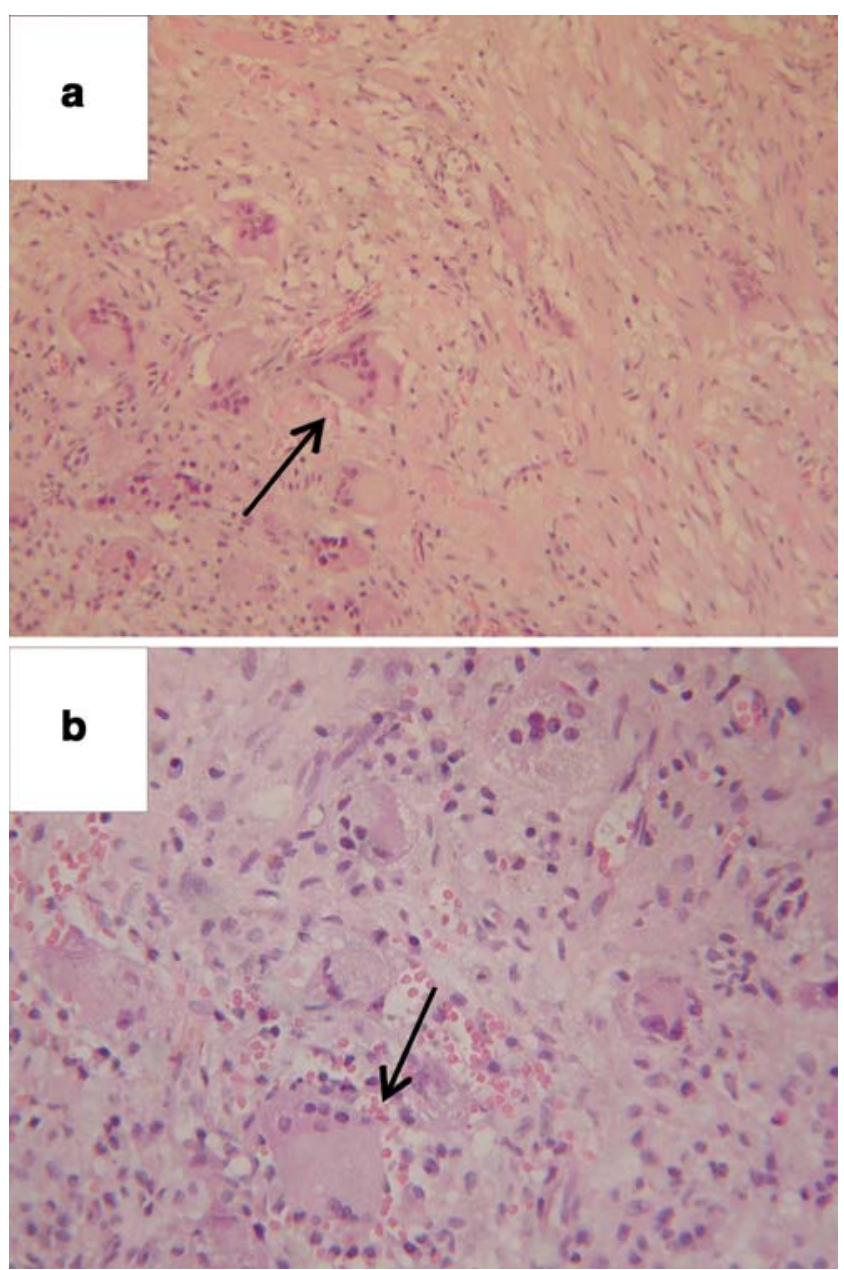

Fig. 4 a H\&E of pelvic biopsy specimen. Detail of giant cell osteoclast-like in GCT (arrow) in an edematous background containing mainly mononuclear cells. b H\&E Neoplastic mononuclear and giant cells infiltrating muscular cells (arrow) of bladder wall

The patient underwent bone biopsy of the pelvis that showed the presence of giant multinucleated cells consistent with GCT (Fig. 4a). This cell population showed a granulomatosis-like pattern of appearance and was associated with lympho-monocyte and eosinophilic components. Biopsy sample obtained from the bladder through a cystoscopy performed for investigation of the hematuria, showed complete integrity of urothelial epithelium, while the chorion and muscolar tunica showed an infiltrate constituted by monuclear cells and giant multinucleated cells within an edematous-myxoid stroma. These features were compatible with ab extrinseco infiltration by the GCT (Fig. 4b).

The patient was started on dexamethasone therapy by intramuscular injections at a dosage of $8-12 \mathrm{mg}$ /day for 3 weeks in combination with intramuscular clodronate $100 \mathrm{mg}$, every 3 days for the first 3 weeks, then weekly. In the subsequent 5 months, dexamethasone was gradually reduced to a daily maintenance dose of $0.75 \mathrm{mg} /$ day given orally. The treatment resulted in a good clinical response with normalization of serum ALP and pain resolution about 1 week after the treatment was started. The patient remained pain-free at the following evaluations performed 1 and 6 months after the beginning of treatment. A control pelvic CT scan performed after 1 and 6 months of therapy indicated a reduction in size of the pelvic mass but persistence of the parietal bladder infiltration. The CT control at 6 months showed a substantial stabilization of the disease, while there was a gradual reduction, until normalization, of serum ALP.

Because of the occurrence of corticosteroid effects and because of the finding of high vascularization of the tumor on angiography, a selective arterial embolization was attempted as an alternative to steroid treatment. Three months after the embolization, the lesion remained stable. However, after suspension of corticosteroid therapy, the patient started experiencing pain in sacral region again which was associated with left leg claudication, and with a new rise in serum ALP levels. Therefore, an alternative treatment was started with intravenous infusion of $4 \mathrm{mg}$ of zoledronic acid every 3 weeks for four cycles and this resulted in good control of bone pain, normalization of the serum ALP but no effect on the tumor size.

Previous reports showed a relatively frequent involvement of mutations of SQSTM1/p62 gene in both sporadic and familial Italian PDB cases [7-9]. Consequently, after obtaining a signed informed consent, genomic DNA extracted from peripheral blood lymphocytes (NucleoSpin Blood Quick Pure, Macherey-Nagel, Easton, PA, USA) and tested for mutations in the SQSTM1/p62 gene coding sequence by automated DNA sequencing (Applied Biosystems, Foster City, CA, USA). However, no mutations were detected.

\section{Discussion}

The occurrence of neoplasms, including osteosarcoma, fibrosarcoma, and chondrosarcoma, as a complication of PDB is an infrequent event $(<1 \%)$ [5]. GCT is an even rarer complication of PDB and the mechanisms involved in the pathogenesis of this tumor are unclear. GCT is usually a benign and remains limited to the bone. Malignant degeneration appears to be a rare event [9].

Treatment of this complication is problematic. A dramatic response to corticosteroid treatment has been reported in a few cases of GCT [10-12]. However, a fairly rapid resumption of disease has also been reported upon steroids discontinuation. In our case, continuous corticosteroid administration contributed to the stabilization of the disease at the clinical, biochemical, and radiological levels. Unfortunately, the lack of mass reduction and the occurrence of corticosteroid side effects required the discontin- 
uation of such therapy. Arterial embolization did not result in significant cytoreduction but intravenous zoledronate led to a good clinical response in terms of pain control and serum ALP reduction.

The visceral and soft tissue infiltration from a GCT has not been reported so far and it highlights the potential malignant behavior of this type of lesions. Interestingly, although mutation of SQSTM1/p62 gene has not been detected, either the familial history (a daughter also affected by PDB) or the early age of occurrence of PDB in both subjects strongly suggested an inherited genetic cause. Thus, our case suggests that different loci could be involved in the pathogenesis of PDB and PDB-related GCT. However, the pathogenesis of PDB and of the GCT remains enigmatic and the role of yet unknown environmental factor (s) such as measles or other viruses $[10,13,14]$ cannot be excluded. Our patient originates from Campania, a region in which a concentration of PDB cases has been previously reported $[10,15,16]$, but not from the rural area of Avellino from where previous cases developing GCT have been reported $[8,16,17]$.

In summary, we present a case of polyostotic PDB complicated by the development of a GCT infiltrating the neighboring tissue in the pelvis including the bladder. The development of GCT in PDB is rare and treatment particularly challenging. A more detailed molecular characterization of known genes and the discovery of new genetic and environmental mechanisms may improve our understanding of GCT and enhance our ability to diagnose and appropriately treat these patients.

Acknowledgments This study was supported by the European Research Program, Fifth Framework Program "Quality of Life and Management of Living Resources Research and Technological Development Program" on "Genetic Markers for Osteoporosis," by the Cofin MIUR, PNR 2001-2003 (FIRB), by the Fondazione Ente Cassa di Risparmio di Firenze, and by the Fondazione FIRMO (to M.L.B). F. Marini is the recipient of a fellowship from the "Jacopo Ficai" grant of the Fondazione Ente Cassa di Risparmio di Firenze. The authors are grateful to Mrs. Debora Strigoli for her technical assistance.

\section{Conflicts of interest None.}

Open Access This article is distributed under the terms of the Creative Commons Attribution Noncommercial License which permits any noncommercial use, distribution, and reproduction in any medium, provided the original author(s) and source are credited.

\section{References}

1. Ralston SH, Langston AL, Reid IR (2008) Pathogenesis and management of Paget's disease of bone. Lancet 372:155-163

2. Laurin N, Brown JP, Morissette J, Raymond V (2002) Recurrent mutation of the gene encoding sequestosome 1 (SQSTM1/p62) in Paget disease of bone. Am J Hum Genet 70:1582-1588

3. Lucas GJ, Daroszewska A, Ralston SH (2006) Contribution of genetic factors to the pathogenesis of Paget's disease of bone and related disorders. J Bone Miner Res 21(Suppl 2):P31-P37

4. Hadjipavlou A, Lander P, Srolovitz H, Enker IP (1992) Malignant transformation in Paget disease of bone. Cancer 70:2802-2808

5. Haibach H, Farrell C, Dittrich FJ (1985) Neoplasms arising in Paget's disease of bone: a study of 82 cases. Am J Clin Pathol 83:594-600

6. Selby PL, Davie MW, Ralston SH, Stone MD (2002) Guidelines on the management of Paget's disease of bone. Bone 31:366-373

7. Wick MR, Siegal GP, Unni KK, McLeod RA, Greditzer HG 3rd (1981) Sarcomas of bone complicating osteitis deformans (Paget's disease): fifty years' experience. Am J Surg Pathol 5:47-59

8. Jacobs TP, Michelsen J, Polay JS, D'Adamo AC, Canfield RE (1979) Giant cell tumor in Paget's disease of bone: familial and geographic clustering. Cancer 44:742-747

9. Leonard J, Gokden M, Kyriakos M, Derdeyn CP, Rich KM (2001) Malignant giant-cell tumor of the parietal bone: case report and review of the literature. Neurosurgery 48:424-429

10. De Chiara A, Apice G, Fazioli F, Silvestro P, Carone G, Manco A (1998) Multicentric giant cell tumor with viral-like inclusions associated with Paget's disease of bone: a case treated by steroid therapy. Oncol Rep 5:317-320

11. Ziambaras K, Totty WA, Teitelbaum SL, Dierkes M, Whyte MP (1997) Extraskeletal osteoclastomas responsive to dexamethasone treatment in Paget bone disease. J Clin Endocrinol Metab 82:3826-3834

12. Kim GS, Kim SH, Cho JK, Park JY, Shin MJ, Shong YK, Lee KU, Han H, Kim TG, Teitelbaum SL, Reinus WR, Whyte MP (1997) Paget bone disease involving young adults in 3 generations of a Korean family. Medicine (Baltimore) 76:157-169

13. Kurihara N, Zhou H, Reddy SV, Garcia Palacios V, Subler MA, Dempster DW, Windle JJ, Roodman GD (2006) Expression of measles virus nucleocapsid protein in osteoclasts induces Paget's disease-like bone lesions in mice. J Bone Miner Res 21:446-455

14. Singer FR, Mills BG (1993) Giant cell tumor arising in Paget's disease of bone. Recurrences after 36 years. Clin Orthop Relat Res 293:293-301

15. Merlotti D, Gennari L, Galli B, Martini G, Calabro A, De Paola V, Ceccarelli E, Nardi P, Avanzati A, Nuti R (2005) Characteristics and familial aggregation of Paget's disease of bone in Italy. J Bone Miner Res 20:1356-1364

16. Rendina D, Gennari L, De Filippo G, Merlotti D, de Campora E, Fazioli F, Scarano G, Nuti R, Strazzullo P, Mossetti G (2006) Evidence for increased clinical severity of familial and sporadic Paget's disease of bone in Campania, southern Italy. J Bone Miner Res 21:1828-1835

17. Rendina D, Mossetti G, Soscia E, Sirignano C, Insabato L, Viceconti R, Ignarra R, Salvatore M, Nunziata V (2004) Giant cell tumor and Paget's disease of bone in one family: geographic clustering. Clin Orthop Relat Res 421:218-224 